\title{
Preliminary Study: Characterisation of Antibody for rLipl32 Protein of Leptospira
}

\author{
Sumarningsih, Tarigan S, Kusmiyati \\ Indonesian Research Center for Veterinary Science \\ Jl. RE Martadinata No. 30, Bogor 16114, West Java, Indonesia \\ drh.sumarningsih@gmail.com
}

\begin{abstract}
Leptospirosis infection is commonly determined by positive response antibody in microaglutination test (MAT). The test requires panels of Leptospira from complete serovars and uses infectious Leptospira, which is subcultured weekly. Accordingly, other alternative serological tests are developed for MAT. One of them is ELISA using recombinant LipL32 protein (rLipL32). High sensitivity and specificity of ELISA rLipL32 for Leptospirosis detection in bovine and canine has been reported previously. In this study, we produced antibody to rLipL32 protein with high titre. Results on western blotting and ELISA showed anti-LipL32 antibody was highly binding to rLipL32 protein. In contrast, MAT results for LipL32 antibody was found to be negative response, indicating that titre antibody to LipL32 does not positively correlate to MAT.
\end{abstract}

Key Words: Leptospira, Antibody Response, LipL32, MAT

\section{INTRODUCTION}

Diagnosis of Leptospirosis can be determined by detection of antigen using isolation of the organism but it is difficult to apply (Cousins et al. 1985; Levett 2001). As a result, OIE (2013) stated that serological microaglutination test (MAT) is the gold standard to diagnose Leptospirosis. However, the MAT has many disadvantages such as: technical difficulties, time consuming and highly contagious agents (Bajani et al. 2003). Another serological test such as ELISA has been developed to overcome this problem by using antigen from whole cell Leptospira or outer membrane protein (OIE 2013).

Protein LipL32 is known as one of Leptospira major outer membrane protein and it is believed as a potential antigen for serological test. It is exposed in the surface of Leptospira cell and can be found as much as 40,000 copies for each cell (Cullen et al. 2005; Malmström et al. 2009). Several studies also reported that LipL32 is an immunodominant protein and plays important role in Leptospirosis infections (Haake et al. 2000; Chaemchuen et al. 2011).

Indonesia is an endemic country for Leptospirosis and application of ELISA LipL32 could be useful as an alternative MAT for diagnostic test. Studies conducted previously by Bomfim et al. (2005) and Dey et al. (2004) reported high sensitivity and accuracy for ELISA LipL32 in bovine and canine, respectively, compared to MAT. However, in our preliminary study using 13 serum sample showed inconsistent results between MAT and ELISA LipL32 for detection of Leptospira in bovine (Sumarningsih et al. 2016). The inconsistent results of the previous study were: some positive sera on MAT showed negative responsense on ELISA LipL32 and some negative sera on MAT were found to be positive on ELISA LipL32. To investigate this contradictory results, further study are required by producing serum anti rLipL32 in rabbit and bovine, and then analyse the correlation between the antibody titre to LipL32 and MAT. 


\section{MATERIAL AND METHODS}

Recombinant LipL32 used to produced antibody to rLipL32 in rabbit and bovine were the result from the previous study conducted by Sumarningsih et.al. (2016). Analysis of antibody titre in this study was performed based on MAT, western blotting, and ELISA rLipL32 techniques.

\section{Production of antibody to rLipL32 protein}

Antibody to LipL32 were produced in rabbit and bovine according to previous study (Yang et al. 2002). One New Zealand rabbit age 10-12 weeks and one bull (Sumbawa male bovine) age 10 months were used to produce antibody to LipL32. Before being imunised, rabbit and bovine sera were collected and tested using MAT to confirm that those animals were negative from Leptospirosis infection. For immunisation, a rabbit was injected intramusculary with $0.4 \mathrm{mg}$ of rLipL32 in complete Freund's adjuvant (Sigma-Aldrich, UK) for first immunisation, followed by $0.4 \mathrm{mg}$ with incomplete Freund's adjuvant (Sigma-Aldrich, UK) as a second and third immunisation, at two week intervals. Sera were collected prior to each immunisation and two weeks after the third immunisation.

For bovine immunisation, $1 \mathrm{mg}$ of recombinant protein was mixed with Montanide ISA $70 \mathrm{M}$ VG (SEPPIC) as adjuvant and used for immunisation. Bovine anti LipL32 serum was collected for LipL32 titre analysis. Similar procedure for MAT was conducted as described by Sumarningsih et al. (2016) to determine the titre of all sera collected in this study.

\section{Western blotting}

Western blotting was carried out according to the previous study with few modification on the blocking buffer and serum dilution (Seenichamy et al. 2014). In brief, antigen rLipL32 protein was transferred into nitrocellulose membrane, and then blocked with $4 \%$ goat normal serum in PBS. The membrane was incubated with rabbit or bovine serum and followed by incubation with 1/5000 HRP coupled to goat-anti-rabbit IgG or goat-anti-bovine IgG, respectively. Antigen-antibody binding was detected by 33'diaminobenzidine tetrahydrochloride (DAB) (Sigma Aldrich Pty Ltd, Castle Hill, NSW).

\section{Enzyme linked-immunosorbent assay (ELISA)}

ELISA was performed using similar procedure to Bomfim et al. (2005) with few modifications on antigen concentration for coating and dilution of primary and secondary antibody. The amount of rLipL32 protein used for coating was $250 \mathrm{ng} /$ well, after being blocked with blocking buffer (PBS-T $0.05 \%+5 \%$ normal goat serum), NUNC maxisorb plate was incubated with primary antibody $(50 \mu \mathrm{l}$ of series of two fold dilution of rabbit or bovine serum started at 1/200), and continued with secondary antibody (50 $\mu 1$ of 1/5000 diluted HRP-goat-anti-rabbit IgGor goat-anti-bovine IgG). At the end, the antigenantibody binding was detected by adding $50 \mu \mathrm{l}$ of ABTS. After 15 minutes, the optical density (OD) was determined at a wavelength of $420 \mathrm{~nm}$ (OD420) using an ELISA reader. 


\section{RESULTS AND DISCUSSION}

\section{Western blotting of anti rLipL32 serum}

Anti LipL32 serum were produced in rabbit and bovine using recombinant LipL32 protein (rLipL32). The functional analysis of antigenicity for this rLipL32 was analysed by western blotting and ELISA. Western blotting demonstrated that rLipL32 were highly binding to serum from rabbit immunized with rLipL32 after second and third immunisation (lane 2 and 3) but not for serum collected from the first immunisation and preimmune (Figure 1). Antigen-antibody binding was also found in serum from bovine immunized with rLipL32 (lane 6) but preimmune bovine serum could not response to LipL32 protein. These results demonstrated that the rLipL32 could induce high antibody response in rabbit and bovine, indicating the high antigenicity and immunogenicity of protein LipL32, as reported from the preliminary study which showed that rLipL32 protein could detect serum from bovine positive MAT (Sumarningsih et al. 2016).

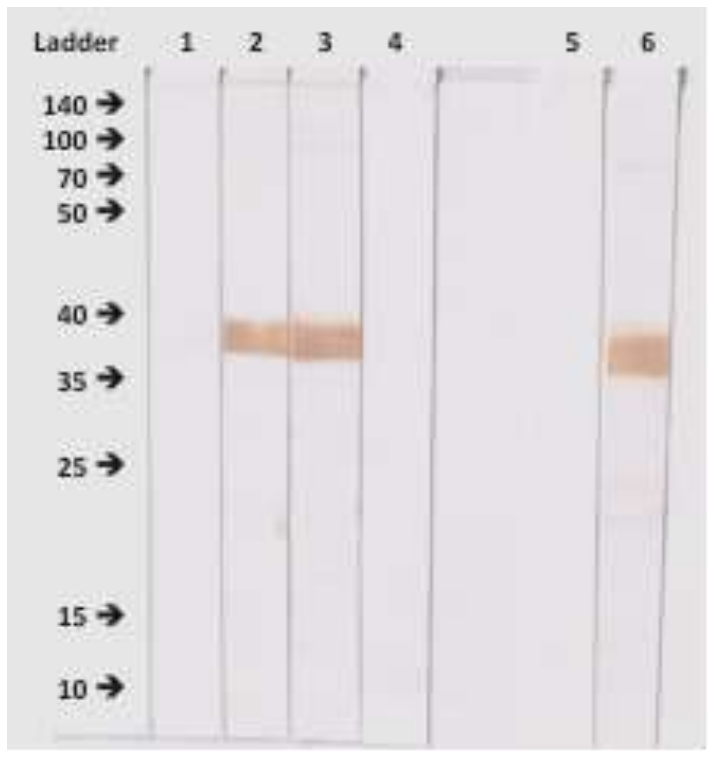

Figure 1. Western blotting of rLipL32 proteins. rLipL32 was subjected to $10 \%$ SDS PAGE, transferred to nitrocellulose membrane and incubated with $1 / 200$ rabbit polyclonal antibody anti rLipL32 2wkPI1 (lane 1), 2wkPI2 (lane 2), 2wkPI3 (lane 3) and 1/200 bovine polyclonal antibody anti rLipL32; Normal rabbit (lane 4) and normal bovine (lane 5) sera were used as negative control

\section{Enzyme linked-immunosorbent assay (ELISA) of anti rLipL32 serum}

Upon the preliminary study, it was determined that $5 \mu \mathrm{g} / \mathrm{ml}$ was the maximum concentration for rLipL32 to binding into microtiter plates. This concentration was then used for coating of rLipL32 protein. Figure 2 showed that the titre of antibody response to LipL32 remained normal in rabbit until two weeks after the first immunisation, but then increased significantly after the second and the third immunisation. For bovine serum, immunisation was performed once due to the limitation of LipL32 product. However, the titre of antibody to LipL32 was significantly high. The difference on method used for rabbit and bovine was the amount of antigen LipL32 applied in serum production. For bovine, it used $1 \mathrm{mg}$ of LipL32 protein, while rabbit only used $0.4 \mathrm{mg}$ of LipL32. Considered the size of rabbit compared to bovine as an experimental animal, the amount of LipL32 used for immunisation should be not the reason for difference antibody titre. 
Another explanation was different adjuvant used for rabbit and bovine. In bovine, Montanide ISA $70 \mathrm{M}$ VG (SEPPIC) was used as an adjuvant, but in rabbit it was both complete and incomplete Freund's adjuvant (Sigma-Aldrich, UK). The further investigation was required to determine whether these two different adjuvant affecting the antibody titre in production of serum anti rLipL32.

(A)

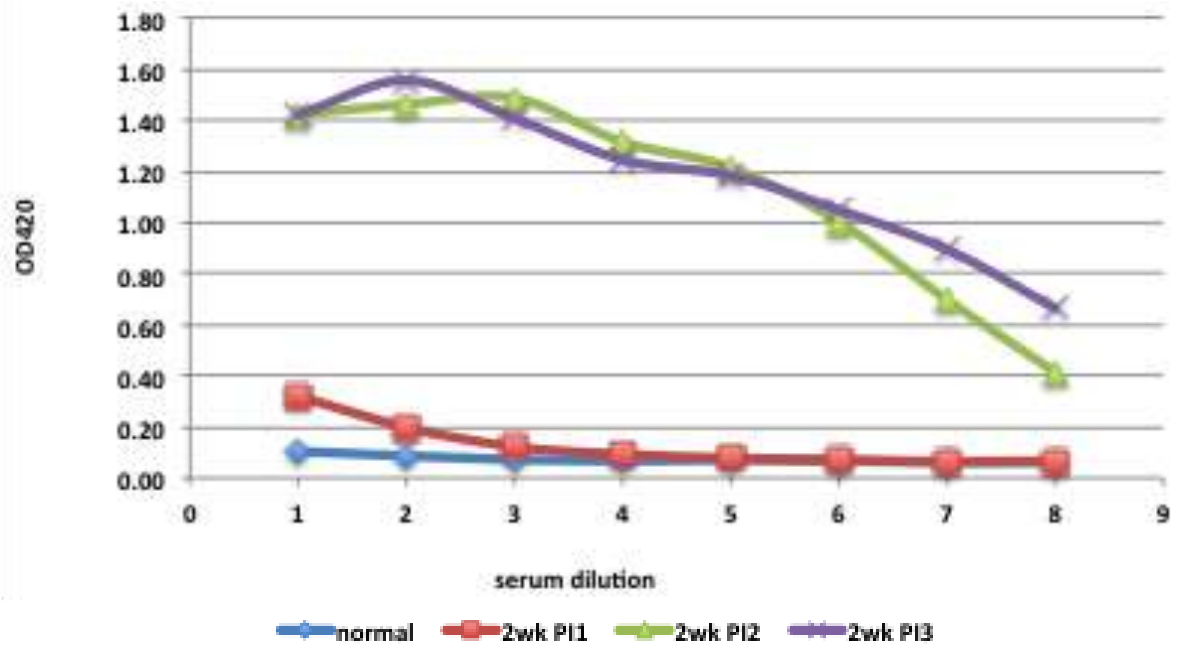

(B)

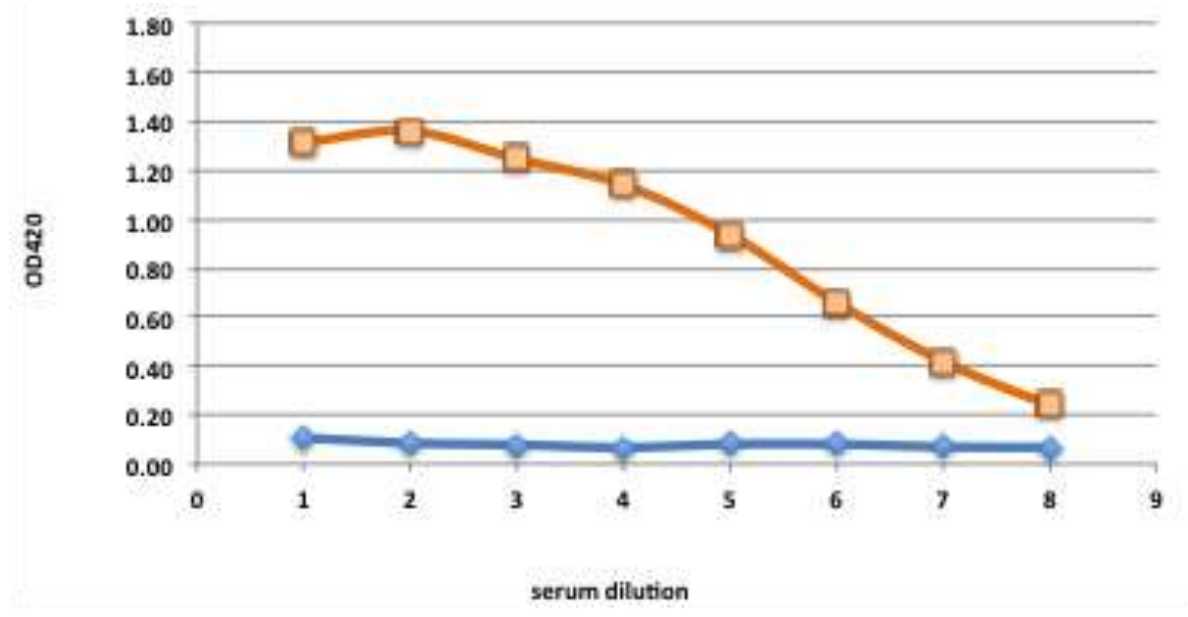

$\Longrightarrow$ normal $\quad=\square=3$ months PI

Figure 2. (A) LipL32 antibody titre in rabbit serum obtained from immunisation with recombinant LipL32 protein at two weeks after the first immunisation (2wk PI1), two weeks after the second immunisation (2wk PI2) and two weeks after the third immunisation (2wk PI3); (B) LipL32 antibody titre in bovine serum obtained from immunisation with recombinant LipL32 protein at three months after immunisation (3months PI); Serum from rabbit and bovine before immunisation (normal) was included as negative control; Serum dilution 1 to 8 represents two folds dilution for $1 / 200$ to $1 / 25600$

The correlation between MAT, western blotting and ELISA results was showed in Table 1, illustrating serum anti LipL32 produced in rabbit and bovine had very high titre, more than 25600 , to recombinant LipL32 protein and it was confirmed by western blotting and ELISA. However, the results in MAT for all sera were negative. This finding indicated that there is no positive correlation between titre antibody to LipL32 and MAT. It is contradictory with previous study which reported antibody response in ELISA LipL32 was highly correlate to MAT (Flannery et al. 2001; Dey et al. 2004; Bomfim et al. 2005). 
Table 1. Summary of MAT, Western blotting and ELISA results for serum anti rLipL32

\begin{tabular}{lllcc}
\hline \hline \multirow{2}{*}{ Serum } & \multirow{2}{*}{ Time of collection } & \multirow{2}{*}{ MAT } & \multicolumn{2}{c}{ Antibody titre to rLipL32 protein } \\
\cline { 4 - 5 } & & & Western blotting & ELISA \\
\hline Rabbit & Preimmune & Negative & Negative & Negative \\
& 2 wk PI-1 & Negative & Negative & Negative \\
& 2 wk PI-2 & Negative & Positive & $>25600$ \\
& 2 wk PI-3 & Negative & Positive & $>25600$ \\
Bovine & Preimmune & Negative & Negative & Negative \\
& 3months PI-1 & Negative & Positive & $>25600$ \\
\hline
\end{tabular}

Correlation between antibody response to LipL32 (ELISA and western blotting) and MAT in the study demonstrated that antibody to LipL32 and MAT are incomparable. In Leptospira infection, antibody to bacterial surface proteins (antigens) plays important role to prevent attachment of the bacterium to the host cell. Pinne and Haake mentioned that LipL32 is entirely or almost entirely located in the subsurface of Leptospira (Pinne \& Haake 2013). Antigen used in MAT was intact cell of Leptospira and it might be a majority of LipL32 exposed in the surface. Therefore, comparison of ELISA LipL32 could be better using other serological tests such as disrupted whole Leptospira cell as an antigen.

\section{CONCLUSION}

Serum anti Lip32 was successfully produced in both rabbit and bovine with high titre more than 25600 in ELISA LipL32, but these serum were found to be negative response in MAT. It is indicated that there is no positive correlation between antibody titre to LipL32 and MAT.

\section{ACKNOWLEDGEMENT}

This work was supported by a grant from the Indonesian Agency for Agriculture Research and Development (IAARD) of the Ministry of Agriculture. We thank Gita Sekarmila, Achpas, Andi Mulyadi, and Agus Wahyudi for technical assistance on performing the assays, and to Dr. Muharam S for providing Montanide ISA $70 \mathrm{M}$ VG (SEPPIC) used in this study.

\section{REFERENCES}

Bajani MD, Ashford DA, Bragg SL, Woods CW, Aye T, Spiegel RA, Plikaytis BD, Perkins BA, Phelan M, Levett PN, Weyant RS. 2003. evaluation of four commercially available rapid serologic tests for diagnosis of leptospirosis. J Clin Microbiol. 41:803-809.

Bomfim MRQ, Ko A, Koury MC. 2005. Evaluation of the recombinant LipL32 in enzyme-linked immunosorbent assay for the serodiagnosis of bovine leptospirosis. Vet Microbiol. 109:89-94.

Chaemchuen S, Rungpragayphan S, Poovorawan Y, Patarakul K. 2011. Identification of candidate host proteins that interact with LipL32, the major outer membrane protein of pathogenic Leptospira, by random phage display peptide library. Vet Microbiol. 153:178-185. 
Cousins DV, Robertson GM, Hustas L. 1985. The use of the enzyme-linked immunosorbent assay (ELISA) to detect the IgM and IgG antibody response to Leptospira interrogans serovars hardjo, pomona and tarassovi in cattle. Vet Microbiol. 10: 439-450.

Cullen PA, Xu X, Matsunaga J, Sanchez Y, Ko AI, Haake DA, Adler B. 2005. Surfaceome of Leptospira spp. Infect Immun. 73: 4853-4863.

Dey S, Mohan CM, Kumar TMAS, Ramadass P, Nainar AM, Nachimuthu K. 2004. Recombinant LipL32 antigen-based single serum dilution ELISA for detection of canine leptospirosis. Vet Microbiol. 103:99-106.

Flannery B, Costa D, Carvalho FP, Guerreiro H, Matsunaga J, Da Silva ED, Ferreira AGP, Riley LW, Reis MG, Haake DA, Ko AI. 2001. Evaluation of recombinant Leptospira antigen-based enzyme-linked immunosorbent assays for the serodiagnosis of leptospirosis. J Clin Microbiol. 39:3303-3310.

Haake DA, Chao G, Zuerner RL, Barnett JK, Barnett D, Mazel M, Matsunaga J, Levett PN, Bolin CA. 2000. The leptospiral major outer membrane protein LipL32 is a lipoprotein expressed during mammalian infection. Infect Immun. 68:2276-2285.

Levett PN. 2001. Leptospirosis. Clin Microbiol Rev. 14:296-326.

Malmström J, Beck M, Schmidt A, Lange V, Deutsch EW, Aebersold R. 2009. Proteome-wide cellular protein concentrations of the human pathogen Leptospira interrogans. Nature. 460:762-765.

Pinne M, Haake DA. 2013. LipL32 is a subsurface lipoprotein of Leptospira interrogans: Presentation of new data and reevaluation of previous studies. PLoS ONE. 8:e51025.

Seenichamy A, Bahaman AR, Mutalib AR, Khairani-Bejo S. 2014. Production and characterization of a polyclonal antibody of anti-rLipL21-IgG against Leptospira for early detection of acute leptospirosis. BioMed Research International. 2014:592858.

Sumarningsih, Tarigan S, Kusmiyati. 2016. Recombinant LipL32 protein for leptospirosis detection in Indonesia. Procedia Chemistry. 18:18-25.

OIE. 2013. Manual of diagnostic tests and vaccines for terrestrial animals. OIE. 4 Februari 2016, from http//www.oie.int/fileadmin/ Home/eng/Health_standards/tahm/2.01.09_LEP TO.pdf.

Yang CW, Wu MS, Pan MJ, Hsieh WJ, Vandewalle, Huang CC. 2002. The Leptospira outer membrane protein LipL32 induces tubulointerstitial nephritis-mediated gene expression in mouse proximal tubule cells. J Am Soc Nephrol. 13:2037-2045. 